\title{
Investigation of Failure Criteria and Experimental Process of the Composite Specimen with Mechanical Joints under Tensile Loading
}

\author{
Pourya Fathi *, Amin Moslemi Petrudi \\ Department of Mechanical Engineering, Tehran University, Iran \\ * Corresponding author email: Pr.Fathi@gmail.com
}

Received: 25 June 2020 / Revised: 30 October 2020 / Accepted: 28 November 2020 / Published: 14 December 2020

\begin{abstract}
Generally, composite materials are used to obtain better engineering properties, including higher hardness, greater strength, lower weight, heat resistance, moisture and corrosion, which are not present in homogeneous materials such as metals, which are more commonly used in composite design. In this article, experimental study of the composite specimen with mechanical joints under tensile loading, joints of composite material structures, failure criteria in composite materials, tensile impact test is investigated. The results of research work it shows that maximum strength, the hand lay-up can be designed with $\left[0^{\circ}, 45^{\circ}, 90^{\circ},-45^{\circ}\right] \mathrm{s}$ and layers with $45^{\circ}$ fibers is very important, because these fibers in these layers have a significant role in increasing the resistance of the piecework under shear stresses due to the passage of stress lines along the hole; In other words, the maximum cut occurs at a $45^{\circ}$ angle, and these layers resist this shear stress.
\end{abstract}

Keywords: Composite, Failure criteria, Mechanical joints.

\section{Introduction}

One of the most important features of composites that is very popular in the military industry. The ability of waves to pass through radio devices within military equipment, such as the joint of a composite missile with a launch controller, radar evasion and non-absorption of waves, resistance to corrosion and chemical agents. Generally, composite materials are used to obtain better engineering properties, including higher hardness, greater strength, lower weight, heat resistance, moisture and corrosion, which are not present in homogeneous materials such as metals, which are more commonly used in composite design [1,2]. Long [3] study on the prediction of delamination in composite multilayers affected by low velocity impacts. In this study, they investigated numerically the Hashin criterion in modeling this issue and ultimately influenced their research through experimental experiments. Singh [4] investigated and compared the strength of composite components with pin joint under tensile loading in three lay-up technique $\left[0^{\circ}, 45^{\circ}, 0^{\circ}\right]$ and $\left[0^{\circ}, 90^{\circ}, 0^{\circ}\right]$ as well as $\left[0^{\circ}, 45^{\circ}, 90^{\circ}\right]$ used. Senthil [5] investigated the effect of fiber angles on the strength of composite components under tensile loading on Sisal-reinforced composite. They examined 6 different patch layers. They performed their experiments with experimental experiments and used electron imaging to extract the results. Jogi [6] investigated the effect of fiber angles on the strength of composite components with epoxy and Kevlar glass fibers under Izod loading and pendulum impact and validated their results with experimental experiments and finally analyzed the impact of angle changes. Liu [7] investigated the impact damage and residual load capacity of composite stepped bonding repairs and joints. The failure mechanism and responses under low velocity impact are still not expressly revealed. A series of experiments for impact are conducted. Responses of impact contact load, deflection, absorbed energy and speed were tested. A critical impact energy of adhesive damage and residual strength was found. Ondurucu [8] investigated progressive failure analysis of glassepoxy laminated composite pinned-joints. The 
damage development process of glass-epoxy laminated composite pinned-joints is investigated. To determine the effects of joint geometry and stacking sequence on the bearing strength and damage mode, experimental studies were carried out. Taghipoor [9] Experimental and numerical study on energy absorption of lattice-core sandwich beam. Quasi-static three-point bending tests on sandwich beams with expanded metal sheets as core were conducted. Relationships between the force and displacement at the mid-span of the sandwich beams were obtained from the experiments. Harhash [10] Experimental characterization and numerical investigations of metal/polymer/metal sandwich composites. the main focus lies on bending conditions, validated by analytical and numerical methods. A wide variety of SPS layer configurations and thicknesses were tested under three-point bending conditions considering different bending angles $\left(60,90\right.$ and $\left.150^{\circ}\right)$ and different punch radii $(1.5,3,6$ and $12 \mathrm{~mm})$. The results are validated in terms of the bending forces, spring back degree, strain field distribution, and thickness reduction. Ruzbahani [11] Experimental Analysis of Composite Sandwich Plates Buckling with Lozenge Core Using the Vibration Correlation Technique. An experimental study of the buckling load of composite sandwich plates with lozenge core has been investigated. The hand lay-up method has been used for fabrication of the composite sandwich plates. One of the specimens was used for the modal test. In order to verify the results of the VCT, the buckling load of four specimens was calculated by the experimental buckling test. The error of VCT was $2.1 \%$. Hence, the efficiency of the VCT for composite sandwich plates with lattice core was confirmed. Li [12] investigated Mechanical and failure properties of rocks with a cavity under coupled static and dynamic loads. The results show that, the dynamic strength of intact specimens and specimens with a cavity decreases with the increase of axial static pressure under $20-70 \%$ of the uniaxial compressive strength. Cheng [13] investigated interfacial bond behaviour between hybrid carbon/basalt fibre composites and concrete under dynamic loading. The hybrid composites have a relatively longer effective bond length under both quasi-static and dynamic loadings. Empirical formulae are proposed based on the test data to predict the dynamic interfacial bonding strength and shear stress between single or hybrid FRP sheet and concrete at various strain rates. Goal of this research, by observing the results, for predicting the strength of multi-layer composite materials under impact loadings. Using the results of the model, one can analyze the distribution and type of stress and strain in each layer of composite.

\section{Joints of composite material structures}

The structures usually result from the joining of members to transfer and tolerate incoming forces. Elements or members of structures include shells, hardeners, frames, and beams that, when joined together, can form various structures such as the wings or body of aircraft, missiles, automobiles, boats, and etc. Joints are usually the weakest points in these structures to integrate these members, and therefore require careful analysis, design and implementation. It usually optimizes weight and price by reducing or simplifying the number of joints. Joints of composite materials structures are generally divided into two groups, adhesive-bonded joints using polymeric adhesives and mechanical joints including screws, rivets, pins, etc. [8]. The strength of a composite structure is a function of the strength of its constituent layers. The process of failure of composites with homogeneous isotropic materials is different due to their non-isotropic nature. In fact, failure in non-isotropic materials can be caused by a variety of stress combinations. In investigating the failure of composites, the behavior of each layer is investigated. When the stress distribution causes a layer to fail, continuation of failure calculations continues with the removal of that layer. Many factors are involved in investigating the failure of composites, the most important of which are the thickness of the composite, the direction of the fibers, the composition of the layers, the mechanical properties and its thermal properties. In discussing the strength of composites, it is necessary to state that the longitudinal strength (in the direction of the fibers) is about 20 times that of the transverse and shear strengths. Therefore, all three components of stress are important in investigating the failure of composites. In general, 
Pourya Fathi \& Amin Moslemi Petrudi, J. Mod. Mater.; Vol. 7, Issue 1, pp: 54-67, 2020

the study of composite failure has many complexities for reasons such as lamination, fiber failure, fiber buckling, resin failure, cavities and cracks, and etc. Table 1 comparison between adhesive-bonded joints and mechanical joints is shown [14]. Figure 1 adhesive-bonded joints in composite materials and Figure 2 Mechanical joints in composite materials and Figure 3 fractures in mechanical joints is shown [8].

Table 1: Comparison between Adhesive-bonded joints and Mechanical joints [14].

\begin{tabular}{|c|c|c|}
\hline $\begin{array}{l}\text { Serial } \\
\text { No. }\end{array}$ & Adhesive-bonded joints & Mechanical joints \\
\hline 1. & $\begin{array}{l}\text { Load distribution over an area instead of being } \\
\text { concentrated at a point }\end{array}$ & $\begin{array}{c}\text { Concentration of load at a point causing } \\
\text { joint failure }\end{array}$ \\
\hline 2. & $\begin{array}{c}\text { As stress distribution is uniform, these joints are } \\
\text { more impervious to fatigue, and flexural and } \\
\text { vibrational stresses }\end{array}$ & $\begin{array}{l}\text { Non-uniform stress distribution resulting in } \\
\text { fatigue cracking }\end{array}$ \\
\hline 3. & Lightweight compared to mechanical joints & Heavy compared to adhesive joints \\
\hline 4. & $\begin{array}{l}\text { Aside from bonding surfaces, adhesive acts as } \\
\text { sealant, thus avoiding galvanic corrosion }\end{array}$ & Prone to galvanic corrosion \\
\hline 5. & Irregular surface can be easily joined. & Joining irregular surfaces is tough \\
\hline 6. & $\begin{array}{c}\text { Smooth contours favorable while outlining } \\
\text { streamlined shapes }\end{array}$ & $\begin{array}{l}\text { Weld heads or fastener heads resulting in } \\
\text { unsmooth contours }\end{array}$ \\
\hline 7. & Cheaper than mechanical joints & Expensive compared to adhesive joints \\
\hline 8. & Cannot be disassembled & Can be easily disassembled \\
\hline 9. & Difficult inspection & Easy inspection \\
\hline
\end{tabular}
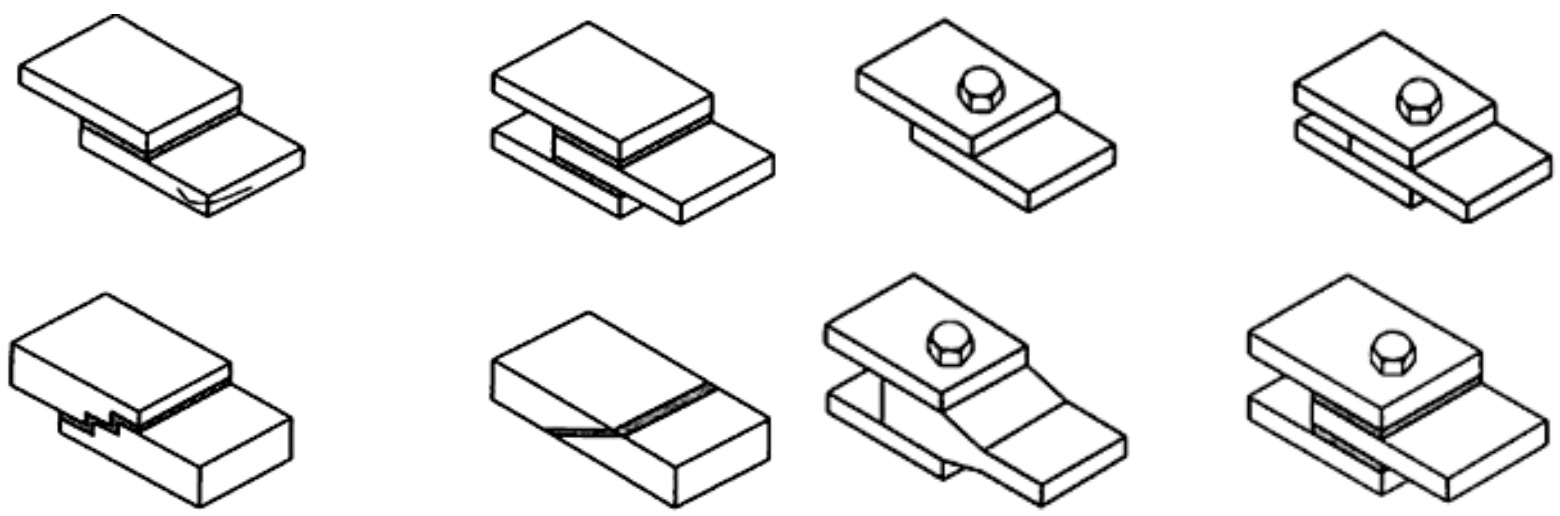

Figure 1: Adhesive-bonded joints in composite

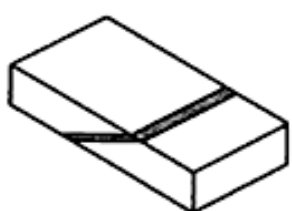
materials [8].

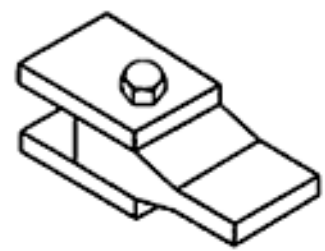

Figure 2: Mechanical joints in composite materials

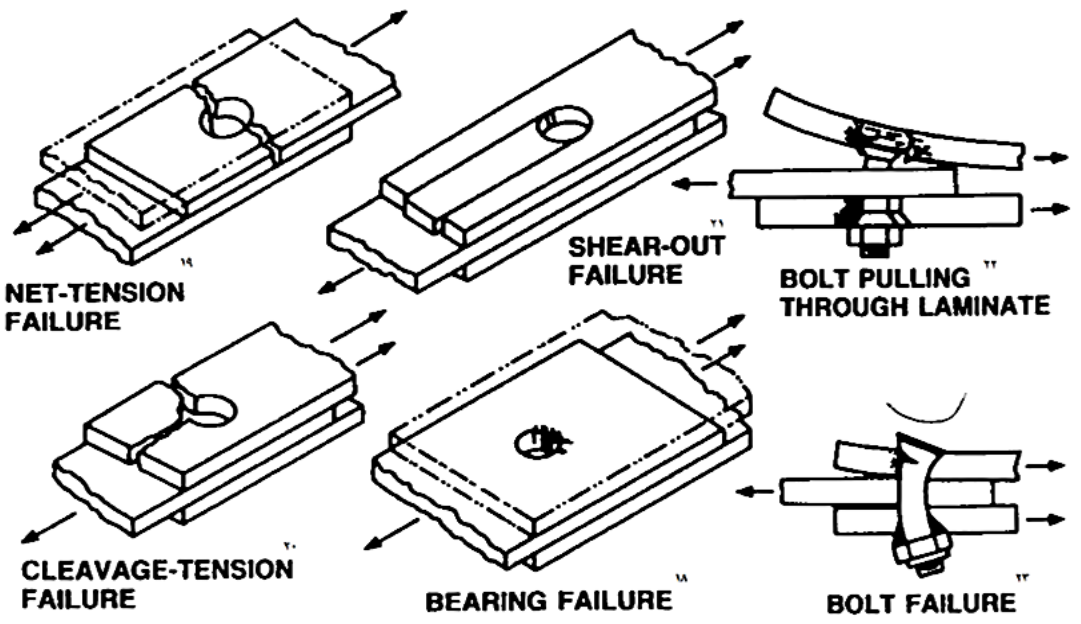

Figure 3: Fractures in mechanical joints [8]. 


\section{Failure criteria in composite materials}

The failure criteria in composites have many variations, each of which is used according to specific conditions. Six main criteria included: maximum stress criterion, maximum strain criterion, Hashin criterion, Hart-Smith criterion, Tsai-Wu theory, Tsai-Hill theory for composite failure. Analysis of the structure of composites under loads using stresses and strains derived from motion and constituent equations. In a composite structure, failure occurs within a layer. Composite materials affected by impact load include three steps: the matrix cracking, delamination and fibers, fiber failure. If the impact load intensity and impact load speed are low, small cracks will first form in the outer layer or in the contact area of the shock absorber and the top layer. This crack will form and grow in the composite matrix. As the impact load increases, cracks formed in the matrix develop, and the composite or fiber layers may disintegrate, forming a delamination. In the last step, if the load velocity of the impact is too high, in addition to creating cracks in the matrix and delamination, the tension in the fibers will increase and the fibers will rupture.

\subsection{Tension-strain relations of an orthopedic plate}

According to Hooke's law, the stress-strain relation is generally expressed as follows:

$$
\sigma_{i}=C_{i j} . \varepsilon_{j} \quad i, j=1, \ldots .6
$$

As $\sigma_{i}$ stress components, $C_{i j}$ hardness matrix components and $\varepsilon_{j}$ strain components. $C_{i j}$ hardness matrix, it has 36 constant coefficients and is a symmetrical matrix due to the strain energy of the hardness matrix. $\left(C_{i j}=C_{j i}\right)$. Therefore, the hardness matrix constants are reduced to 21. This matrix has different coefficients according to the properties of the material. As non-isotropic materials, the hardness matrix has no symmetry plate and has 21 independent coefficients, For monoclinic materials, the hardness matrix has a symmetry plate and 13 independent coefficients, For orthotropic materials, the hardness matrix has three vertical symmetry plates and 9 independent coefficients, and for isotropic materials, the hardness matrix has an infinite symmetry plane and 2 independent coefficients. Layered composites are usually orthopedic in terms of fiber and matrix properties, and the stress-strain relations for a single layer in the main directions in fixed engineering terms is as follows :

$$
\left\{\begin{array}{c}
\varepsilon_{1} \\
\varepsilon_{2} \\
\varepsilon_{3} \\
\gamma_{23} \\
\gamma_{31} \\
\gamma_{12}
\end{array}\right\}=\left[\begin{array}{cccccc}
\frac{1}{E_{1}} & -\frac{v_{21}}{E_{2}} & -\frac{v_{31}}{E_{3}} & 0 & 0 & 0 \\
-\frac{v_{12}}{E_{1}} & \frac{1}{E_{2}} & -\frac{v_{32}}{E_{3}} & 0 & 0 & 0 \\
-\frac{v_{13}}{E_{1}} & -\frac{v_{23}}{E_{2}} & \frac{1}{E_{3}} & 0 & 0 & 0 \\
0 & 0 & 0 & \frac{1}{G_{23}} & 0 & 0 \\
0 & 0 & 0 & 0 & \frac{1}{G_{31}} & 0 \\
0 & 0 & 0 & 0 & 0 & \frac{1}{G_{12}}
\end{array}\right]\left\{\begin{array}{c}
\sigma_{1} \\
\sigma_{2} \\
\sigma_{3} \\
\tau_{23} \\
\tau_{31} \\
\tau_{12}
\end{array}\right\}
$$

Directions 1 and 2 are parallel and perpendicular to the direction of the layer, and direction 3 is perpendicular to directions 1 and 2. Assuming the layer is thin and the tension of the plate ) $\left(\sigma_{3}=0, \tau_{23}=0, \tau_{31}=0\right.$ and writing stresses in terms of strain, the strain-strain relations is summarized as follows:

$$
\left\{\begin{array}{c}
\sigma_{1} \\
\sigma_{2} \\
\tau_{12}
\end{array}\right\}=\left[\begin{array}{ccc}
Q_{11} & Q_{12} & 0 \\
Q_{12} & Q_{22} & 0 \\
0 & 0 & Q_{66}
\end{array}\right]\left\{\begin{array}{l}
\varepsilon_{1} \\
\varepsilon_{2} \\
\gamma_{12}
\end{array}\right\}
$$

Due to the fact that the structure is composed of several layers, each of which has different fiber directions and as a result the material coordinate systems (main directions) are different, their matrix of hardness, stress and strain are defined in their devices. Therefore, it is necessary to transfer the whole layer to the general coordinate system. Figure 4 shows an example of a multilayer [15].

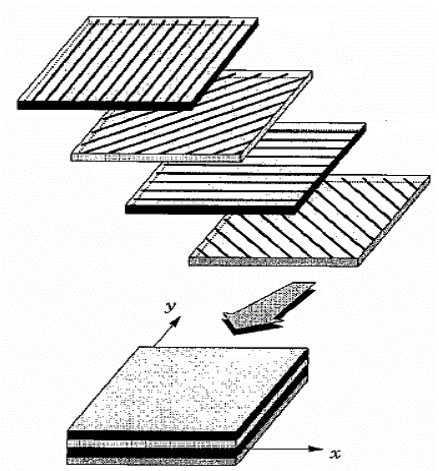

Figure 4: Multilayer consisting of several layers with different fiber angles [15]. 
Such criteria are all in the form of a polynomial and tensor phrase that uses mathematical expressions that depend on the strength of the material to describe the level of failure of the material. And is based on laboratory tests. The most common failure criteria for this group of criteria for composite materials are Tsai criterion [16].

\subsection{Failure criteria without considering failure modes}

$$
\begin{aligned}
F i . \sigma i+F i j . \sigma i . \sigma j+ \\
F i j k . \sigma i . \sigma j . \sigma k>1
\end{aligned}
$$

As $i, j, k=1, \ldots, 6$ for 3D mode. Parameters $F_{i}, F_{i j}$ and $F_{i j k}$ it is related to the resistance of the layer in the main directions. Such theories are not used for materials that have different failure mechanisms. Therefore, it can be used for materials that are isotropic and homogeneous in structure. Due to the non-homogeneous properties of the composite material, the theories of the second group are suggested.

\subsection{Failure criteria by considering failure modes}

In these criteria, different failure modes are investigated and therefore they are suitable for damage analysis. Some of the criteria in this category, such as the maximum strain and maximum stress criteria, do not take into account the effects of stress and interaction on the failure mode, and others, such as the Hashin criterion, have considered these interactions. Each of them will be described below.

\section{A) Maximum strain criterion}

In the maximum strain criterion, the material fails when the strain rate exceeds the allowable limit of the material in each direction, and is expressed as three different fracture modes of fibers, matrix, and shear. The maximum strain criterion is one of the criteria that has already considered the effects of stress interaction on each other [17].

Fiber failure mode

$$
\begin{aligned}
& \varepsilon_{1} \geq \varepsilon^{\mathrm{u}_{1 \mathrm{~T}}} \quad \text { for } \quad \varepsilon_{1} \geq 0 \quad, \quad\left|\varepsilon_{1}\right| \geq \\
& \varepsilon^{\mathrm{u}_{1 \mathrm{C}}} \quad \text { for } \varepsilon_{1} \leq 0
\end{aligned}
$$

Matrix failure mode

$$
\begin{aligned}
& \varepsilon_{2} \geq \varepsilon^{u_{2 T}} \quad \text { for } \quad \varepsilon_{2} \geq 0 \quad, \quad\left|\varepsilon_{2}\right| \geq \\
& \varepsilon^{u_{2 C}} \quad \text { for } \varepsilon_{2} \leq 0
\end{aligned}
$$

Shear failure mode

$$
\left|\varepsilon_{12}\right| \geq \varepsilon^{\mathrm{u}}{ }_{12}
$$

\section{B) Maximum stress criterion}

In this criterion, failure occurs when stress exceeds the allowable limit in the material. This criterion is also one of the criteria that do not consider the interaction of stresses on each other and consists of three modes of fiber failure, matrix and shear [17].

Fiber failure mode

$$
\begin{aligned}
& \sigma_{11} \geq \sigma^{u_{11 \mathrm{~T}}} \quad \text { for } \quad \sigma_{11} \geq 0 \\
& \left|\sigma_{11}\right| \geq \sigma^{u_{11 \mathrm{C}}} \quad \text { for } \sigma_{11} \leq 0
\end{aligned}
$$

Matrix failure mode

$$
\begin{aligned}
& \sigma_{22} \geq \sigma^{\mathrm{u}_{22 \mathrm{~T}}} \quad \text { for } \quad \sigma_{22} \geq 0 \\
& \left|\sigma_{22}\right| \geq \sigma^{\mathrm{u}_{22 \mathrm{C}}} \quad \text { for } \sigma_{22} \leq 0
\end{aligned}
$$

Shear failure mode

$$
\left|S_{12}\right| \geq \mathrm{Su}_{12}
$$

\section{C) Hashin Criterion}

In this article, the Hashin criterion is used and this criterion is considered as three-dimensional. It consists of different failure modes such as tensile and compressive failure modes of fibers, tensile and compressive failure modes of matrix, shear failure modes and tensile and compression failure modes. These criteria are considered to be the interaction of stress in the layers. Figure 5 failure plates based on Hashin criteria is shown [18].

\section{fiber modes failure plane}

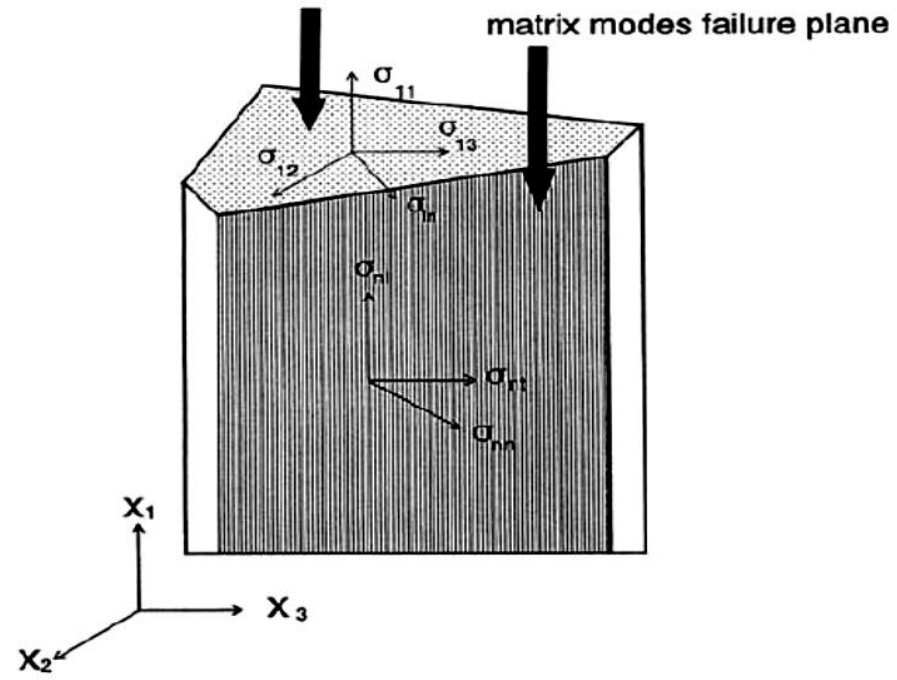

Figure 5: Failure plates based on Hashin criteria [18]. 
Matrix tensile failure mode for $\sigma_{22}>0$

$$
\left(\frac{\sigma_{22}}{\sigma_{22 T}^{u}}\right)^{2}+\left(\frac{S_{12}}{S_{12}^{u}}\right)^{2}+\left(\frac{S_{23}}{S_{23}^{u}}\right)^{2} \geq 1
$$

Matrix compression failure mode for $\sigma_{22}<0$

$$
\left(\frac{\sigma_{22}}{\sigma_{22 C}^{u}}\right)^{2}+\left(\frac{S_{12}}{S_{12}^{u}}\right)^{2}+\left(\frac{S_{23}}{S_{23}^{u}}\right)^{2} \geq 1
$$

Fiber tensile failure mode for $\sigma_{11}>0$

$$
\left(\frac{\sigma_{11}}{\sigma_{11 T}^{u}}\right)^{2}+\left(\frac{S_{12}}{S_{12}^{u}}\right)^{2}+\left(\frac{S_{13}}{S_{13}^{u}}\right)^{2} \geq 1
$$

Fiber compression failure mode for $\sigma_{11}<0$

$$
\left(\frac{\sigma_{11}}{\sigma_{11 C}^{u}}\right)^{2} \geq 1
$$

Fiber-matrix shear failure mode for $\sigma_{11}<0$

$$
\left(\frac{\sigma_{11}}{\sigma_{11 C}^{u}}\right)^{2}+\left(\frac{S_{12}}{S_{12}^{u}}\right)^{2}+\left(\frac{S_{13}}{S_{13}^{u}}\right)^{2} \geq 1
$$

Cleavage failure mode for $\sigma_{33}>0$

$$
\left(\frac{\sigma_{33}}{\sigma_{33 T}^{u}}\right)^{2}+\left(\frac{S_{13}}{S_{13}^{u}}\right)^{2}+\left(\frac{S_{23}}{S_{23}^{u}}\right)^{2} \geq 1
$$

Cleavage failure mode for $\sigma_{33}<0$

$$
\left(\frac{\sigma_{33}}{\sigma_{33 C}^{u}}\right)^{2}+\left(\frac{S_{13}}{S_{13}^{u}}\right)^{2}+\left(\frac{S_{23}}{S_{23}^{u}}\right)^{2} \geq 1
$$

\section{Experimental Study}

One of the most important properties is the strength of the composites in mechanical coupling. For this purpose, the method of fabricating and conducting experimental tests on composite specimen with mechanical coupling (PIN) under tensile loading is investigated. First, we will explain how to build a multilayer, and then prepare it for impact traction testing. In this study, a composite and symmetrical plate (length L, width W, thickness t) with materials consisting of fiberglass fabrics in $0^{\circ}$ and $90^{\circ}$ directions and epoxy resin were fabricated. The plate is investigated from 8 layers

\begin{tabular}{|c|c|c|}
\hline Properties & $\begin{array}{l}\text { Glass / Epoxy } \\
\text { (unidirectional) }\end{array}$ & Unit \\
\hline $\begin{array}{l}\text { Longitudinal } \\
\text { elastic modulus }\end{array}$ & $39 \times 10^{6}$ & $\mathrm{E}_{1}\left(\mathrm{~N} / \mathrm{mm}^{2}\right)$ \\
\hline $\begin{array}{l}\text { Transverse elastic } \\
\text { modulus }\end{array}$ & $8 / 6 \times 10^{6}$ & $\mathrm{E}_{2}\left(\mathrm{~N} / \mathrm{mm}^{2}\right)$ \\
\hline Shear modulus & $3 / 8 \times 10^{6}$ & $\mathrm{G}_{12}\left(\mathrm{~N} / \mathrm{mm}^{2}\right)$ \\
\hline $\begin{array}{l}\text { Ultimate } \\
\text { longitudinal tensile } \\
\text { strength }\end{array}$ & 1080 & $\mathrm{X}_{\mathrm{t}}(\mathrm{MPa})$ \\
\hline $\begin{array}{c}\text { Ultimate } \\
\text { longitudinal } \\
\text { pressure strength }\end{array}$ & 620 & $\mathrm{X}_{\mathrm{c}}(\mathrm{MPa})$ \\
\hline $\begin{array}{c}\text { Ultimate } \\
\text { transverse tensile } \\
\text { strength }\end{array}$ & 39 & $\mathrm{Y}_{\mathrm{t}}(\mathrm{MPa})$ \\
\hline $\begin{array}{c}\text { Ultimate } \\
\text { transverse pressure } \\
\text { strength }\end{array}$ & 128 & $\mathrm{Y}_{\mathrm{c}}(\mathrm{MPa})$ \\
\hline $\begin{array}{l}\text { Ultimate plate } \\
\text { shear stress }\end{array}$ & 89 & $\mathrm{~S}(\mathrm{MPa})$ \\
\hline $\begin{array}{l}\text { Ultimate shear } \\
\text { strength of the } \\
\text { plate }\end{array}$ & 35 & $\mathrm{~S}(\mathrm{MPa})$ \\
\hline Poisson's ratio & 0.28 & $v(-)$ \\
\hline Density & $1760 \times 10^{6}$ & $\left(\mathrm{~kg} / \mathrm{mm}^{2}\right) \rho$ \\
\hline
\end{tabular}
with a layer of $\left[0^{\circ} .90^{\circ} 45^{\circ}\right.$ and $\left.-45^{\circ}\right] \mathrm{s}$ which is symmetric and isotropic with respect to the layer.
Table 2 mechanical Joints properties of composite material is shown [18].

Table 2: Mechanical Joints properties of composite material [18].

First, the fabric of the desired glass fibers is selected according to the appropriate properties and conditions of the test and standards, then according to the dimensions and direction of the specified lay-up of the piecework with predetermined patterns in angles 0 and 90 as well as 45 and (-45) The degree is cut in the direction of the fibers. Dacron fabric and mesh fabric are also cut according to the dimensions of the original fabric and of course $10 \mathrm{~cm}$ larger on each side. The multi-layered composite plate is made with dimensions of about $12 \times 30 \mathrm{~cm}$. The fabric used in the composite sheets is cut from each side according to the dimensions of the main fabric, which is shown in Figure 6. In the following 
experimental work, the type of fabric used and its appropriate selection is of special importance, which is shown in Figure 7 fabrics used in composites plats.
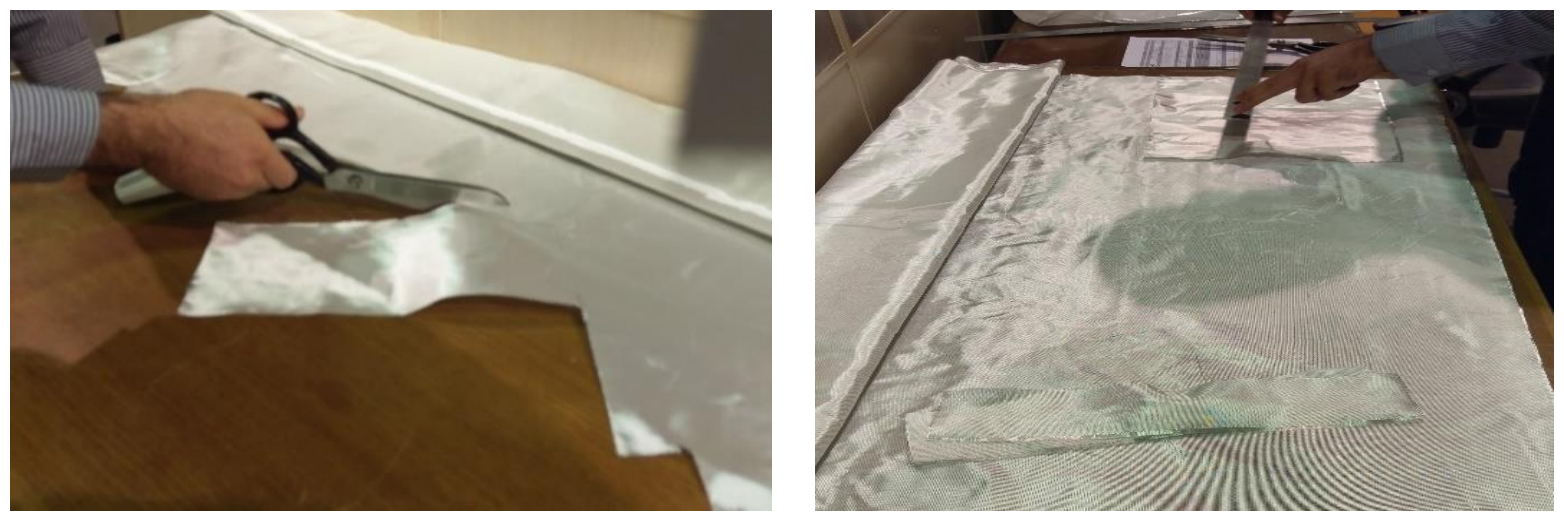

Figure 6: Cutting and measuring fabrics.

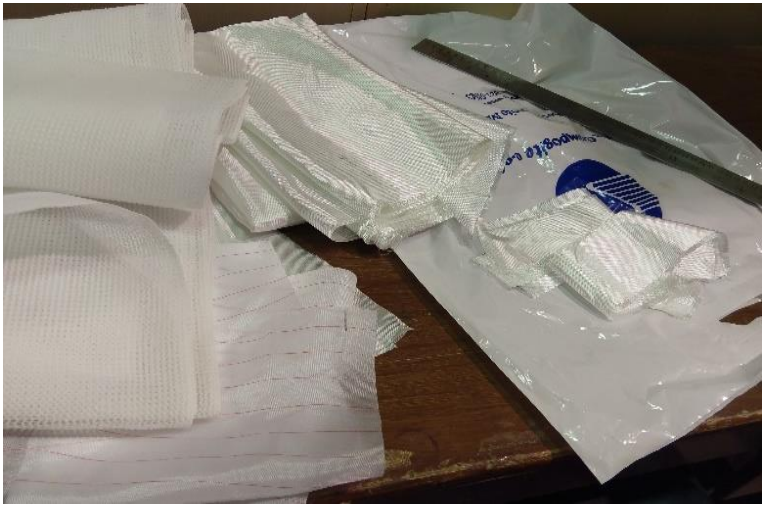

Choose the suitable fabrics.

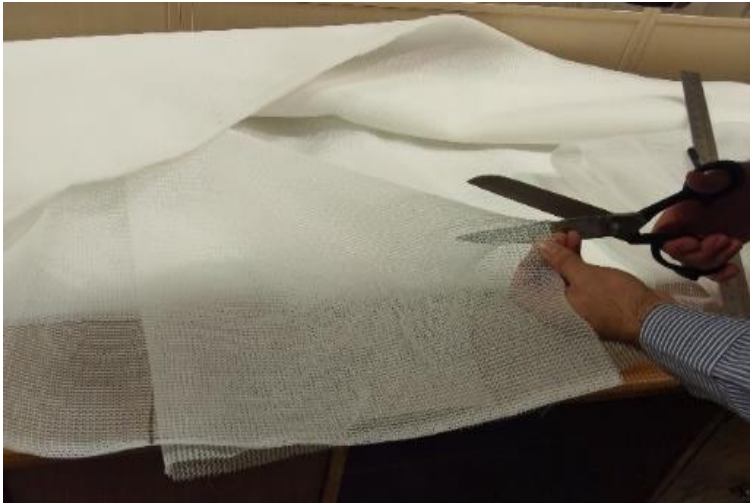

Cut mesh and Dacron fabric.

Figure 7: Fabrics used in composite plates.

The large glass plate is selected and placed on the work table according to the size of the desired piecework. The glass is then cleaned with a special wax so that the specimen can be easily removed. At this stage, the fabric layering begins. First, a layer of Dacron fabric is placed on the glass surface. The reason for this is that the part does not stick to the glass and creates an uneven and non-polished surface of the specimen, which later does not need to be sanded to the parts to be placed in the test machine. The next layer is the mesh fabric. Mesh fabric for high-layer parts is laid both under the layup and on the lay-up of the desired fibers, but in this example, because the number of layers is 4 layers of two directions, there is no need for two layers of mesh fabric and only the top or bottom of the lay-up is placed. The next layer is again the Dacron fabric to prevent the mesh fabric from sticking to the piecework. At this stage, the lay-up of the piecework begins: glass fibers 0 and 90 , glass fibers 45 and (-45), glass fibers 45 and (-45), glass fibers 0 and 90, Dacron fabric.

After finishing the lay-up around the glass, the sealing paste is adhesived. Then two types of pipes are installed on the glass to apply the resin to the piecework. There are two types of pipes, the first of which is a simple pipe, one for pulling resin from the container and the other for removing air and excess resin. The second type of pipe, that location is very important and is called strategic injection, and their location has a great impact on the duration of the injection. To make this specimen, spiral pipes are installed during the work to reduce the injection time. The second type of pipe is a pipe that is spiral-shaped, so that the resin can easily entry or exit. It is very important to choose the type of pipe, it is better to use polyurethane pipes so that the pipe does not vacuum when applied. The spiral pipe is also placed on the top and bottom of the piecework to 
easily spread the resin on the surface of the piecework and at the end add resin and collect air from the piecework. After determining the installation location, the pipes are fixed in place with adhesive or sealing paste. The head of the resin suction pipe is closed, and the next pipe is connected to the resin trap container and then to the pump.

The vacuum bag is pulled over the entire work, and by checking around the work, you should make sure that the chamber between the bag and the glass is ensured. The pump is turned on and discharges all the air in the chamber and continues to discharge under specific pressures. The connected pipe is then separated from the resin trap container and fastened so that the vacuum inserted in the chamber is not removed. The prepared set is discarded for a few hours, due to the fact that the chamber is sealed so that it can be ensured that it does not penetrate into the air during resin application and that the resin does not leak from any point. After a few hours, the set is reconnected to the pump. The applied pressure is 0.7 atmospheric pressure. At this stage, the closed end of the pipe is placed inside the resin side and the resin injection is started. The resin slowly begins to move through the pipes and fabrics, first penetrating the mesh fabric, then the glass fibers. The injection time for this piecework is about 6-8 minutes to fill the entire resin of the work surface. The amount of resin used was about $140 \mathrm{~g}$. Figure 8 Cleaning the glass surface and waxing and then stick the sealing paste around the work and adjust the layer of Dacron fabric and start layering the glass fibers. In Figure 9, after selecting the

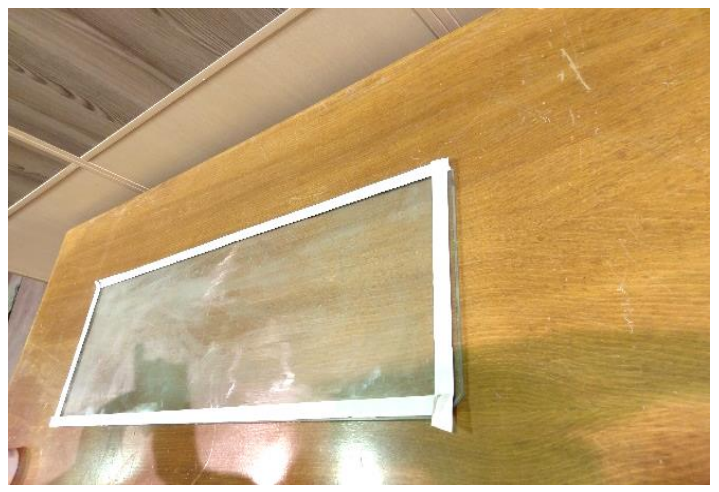

Stick the sealant around the work.
Dacron layer and the mesh, the injection strategy is started installation of sealing pipes and paste in resin injection screw pipes the pump and the resin trap container are set together and started. In Figure 10, the injection steps are initiated under vacuum conditions and the vacuum applied to ensure system sealing and resin injection occurs under vacuum conditions. Then in Figure 11 the injection time for this piecework and the amount of resin used determines the composition of the resin with the hardener. Figure 12 specimen weight percentage chart is shown. The stage of resin injection in a vacuum and after the plate is completely dry, open the bag and the plate comes out of the chamber, which is the stage of finishing the injection and cutting the plates with the exact dimensions of the cut piece, which is shown in Figure 13. To avoid problems during drilling, the plates are carefully taken by special tools that determine the location of drilling, drilling parts, drilling plates, pin connections in the specimens, which is shown in Figure 14. The specimens before the test show that the minimum number of tests experimented for the accuracy of the obtained data is 5 tests. According to this standard, 5 specimens were prepared and tests were performed on these specimens shown in Figure 15. Figure 16 shows a failure specimen in the jaw of the device after a multi-stage test. Figure 17 , the failure specimens, which after performing the test at the test machine show the failure energy number. Figure 18, the direction of failure in the specimen under the experimental test and as seen in the results, the red elements show the onset of failure experimental tests.

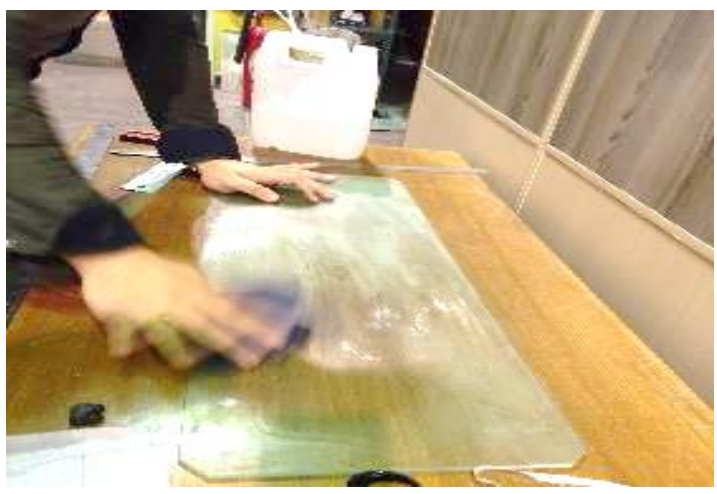

Cleaning the glass surface and wax. 
Pourya Fathi \& Amin Moslemi Petrudi, J. Mod. Mater.; Vol. 7, Issue 1, pp: 54-67, 2020

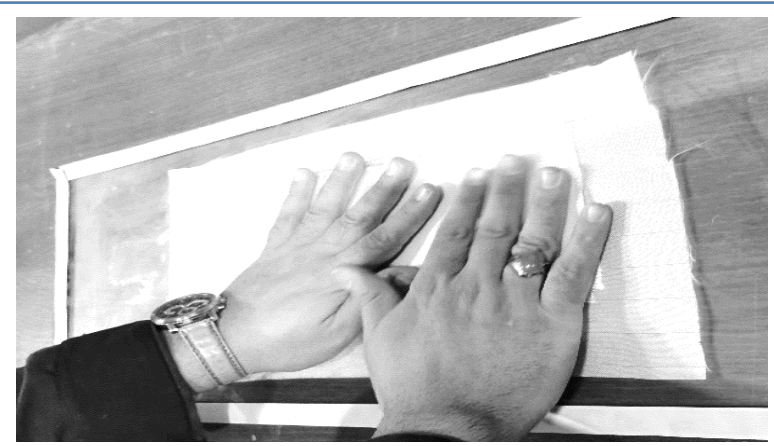

The beginning of the lay-up of glass fibers.

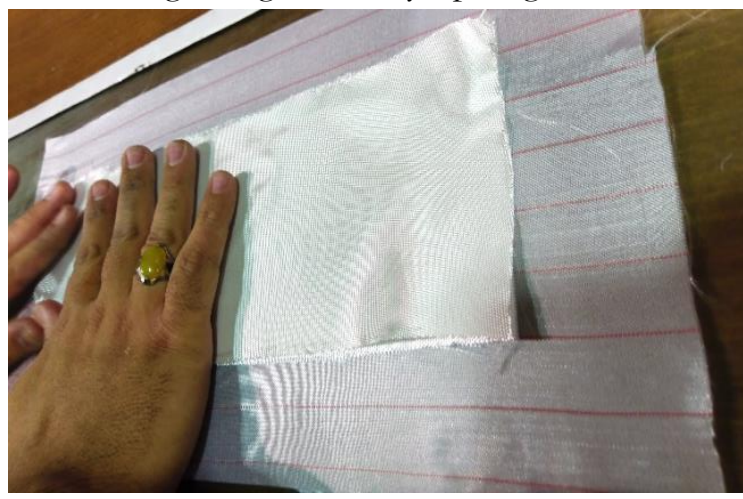

lay-up of glass fibers.

Figure 8: Stages of fiber hand lay-up.

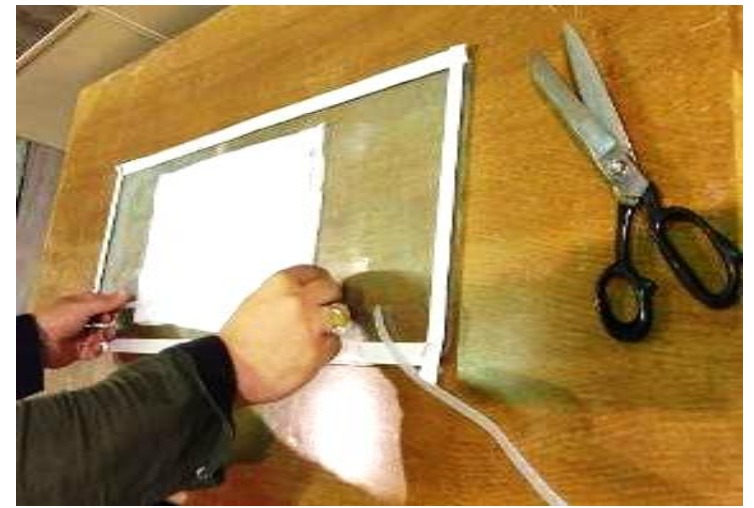

Injection strategy.

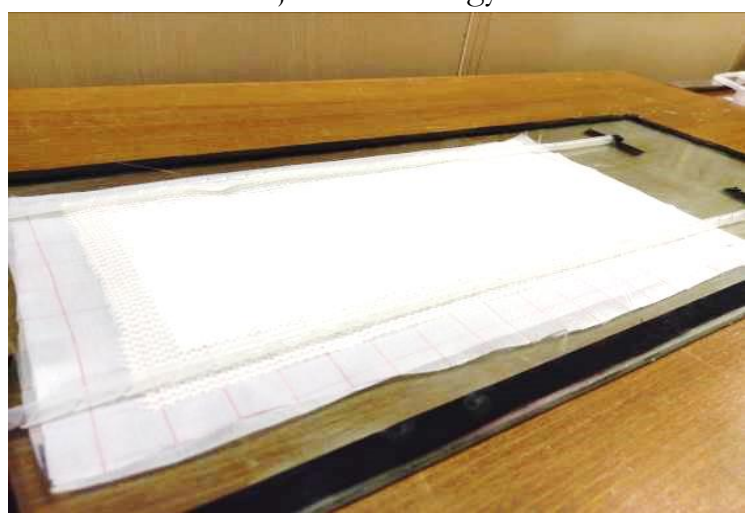

Spiral pipes resin injection.

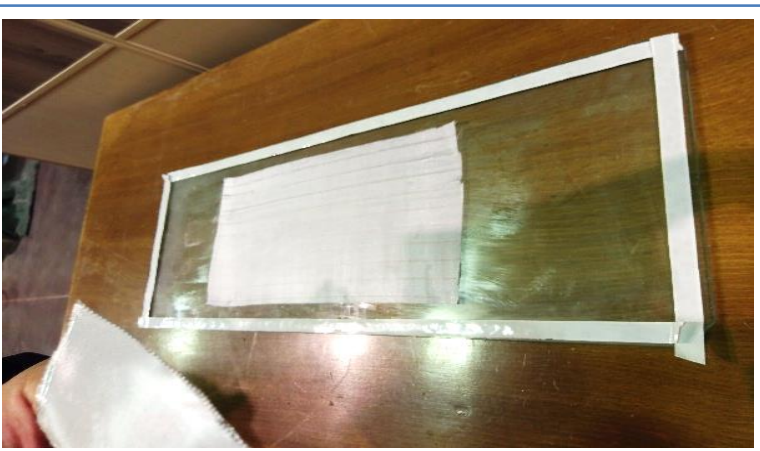

Dacron fabric layer.

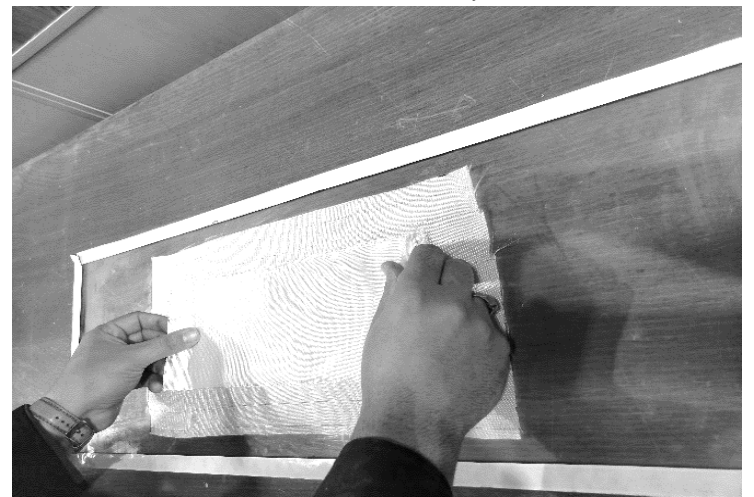


Investigation of Failure Criteria and Experimental Process of the Composite

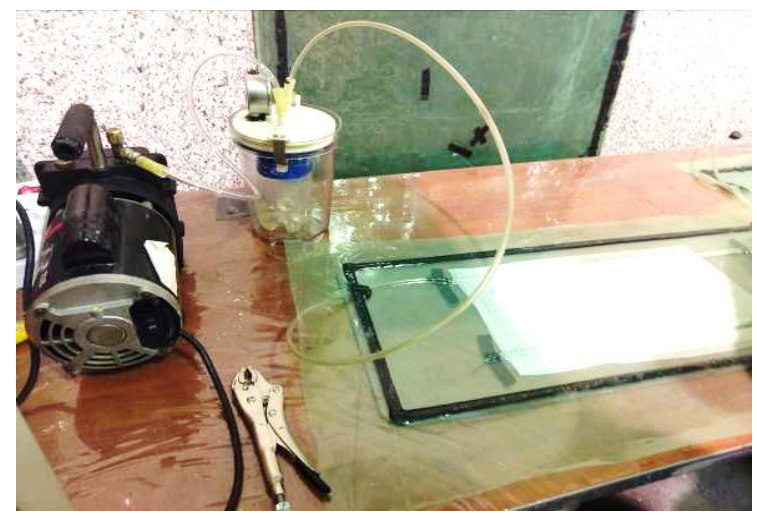

Pump and resin trap container.

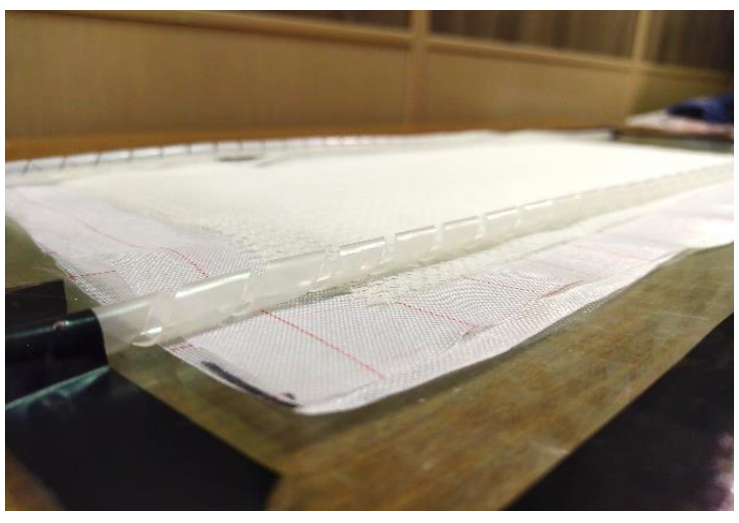

Spiral pipes resin injection.

Figure 9: Injection strategy stages.

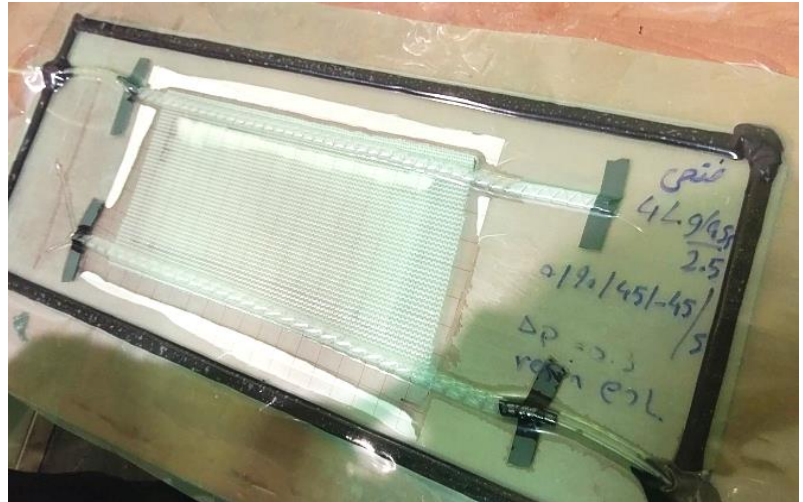

Resin injection in vacuum conditions.

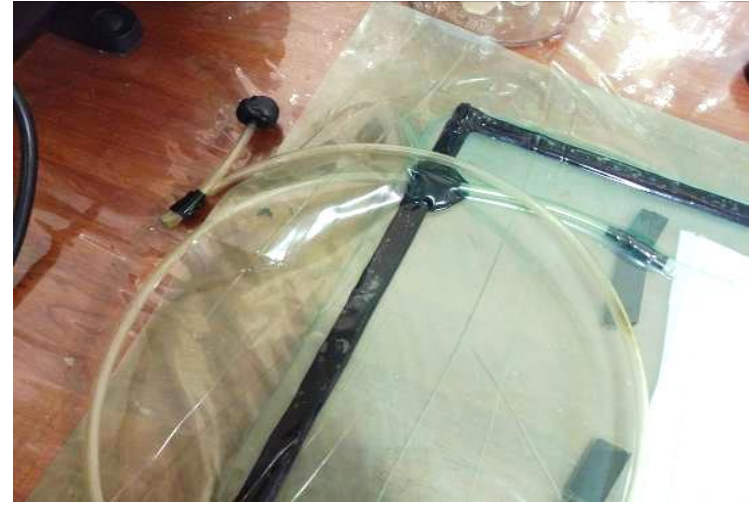

Vacuum applied to ensure system sealing.

Figure 10: Injection stages under vacuum conditions.
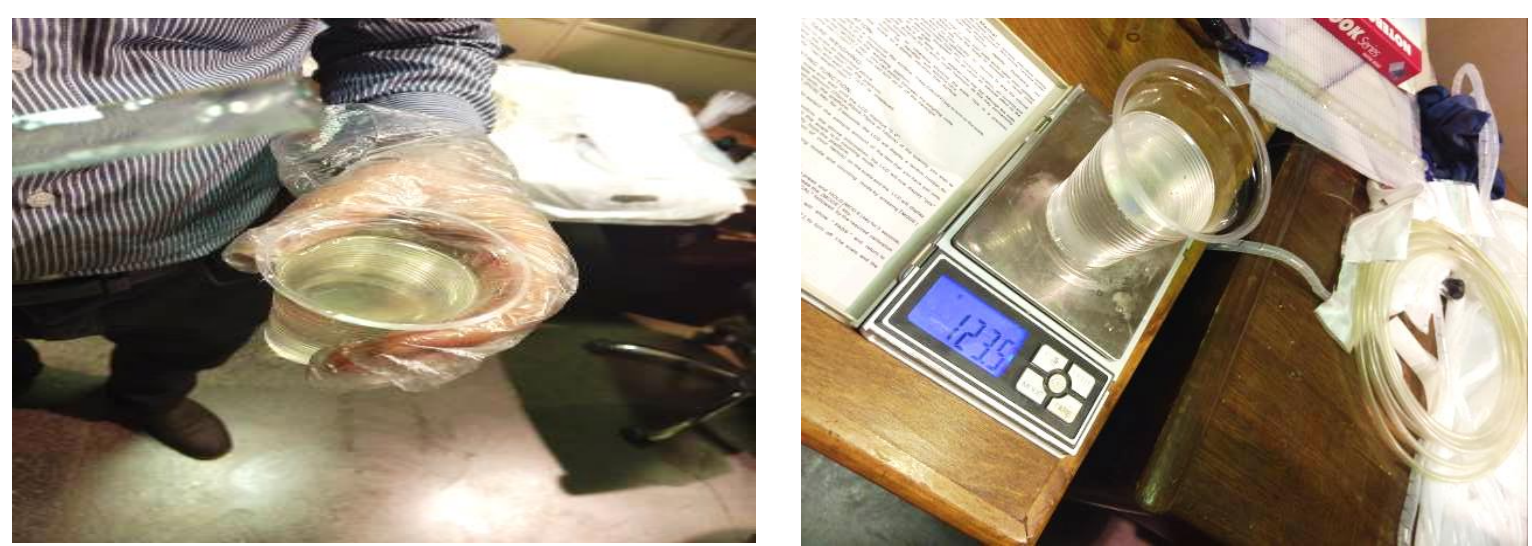

Figure 11: Combine resin with hardener. 
Pourya Fathi \& Amin Moslemi Petrudi, J. Mod. Mater.; Vol. 7, Issue 1, pp: 54-67, 2020
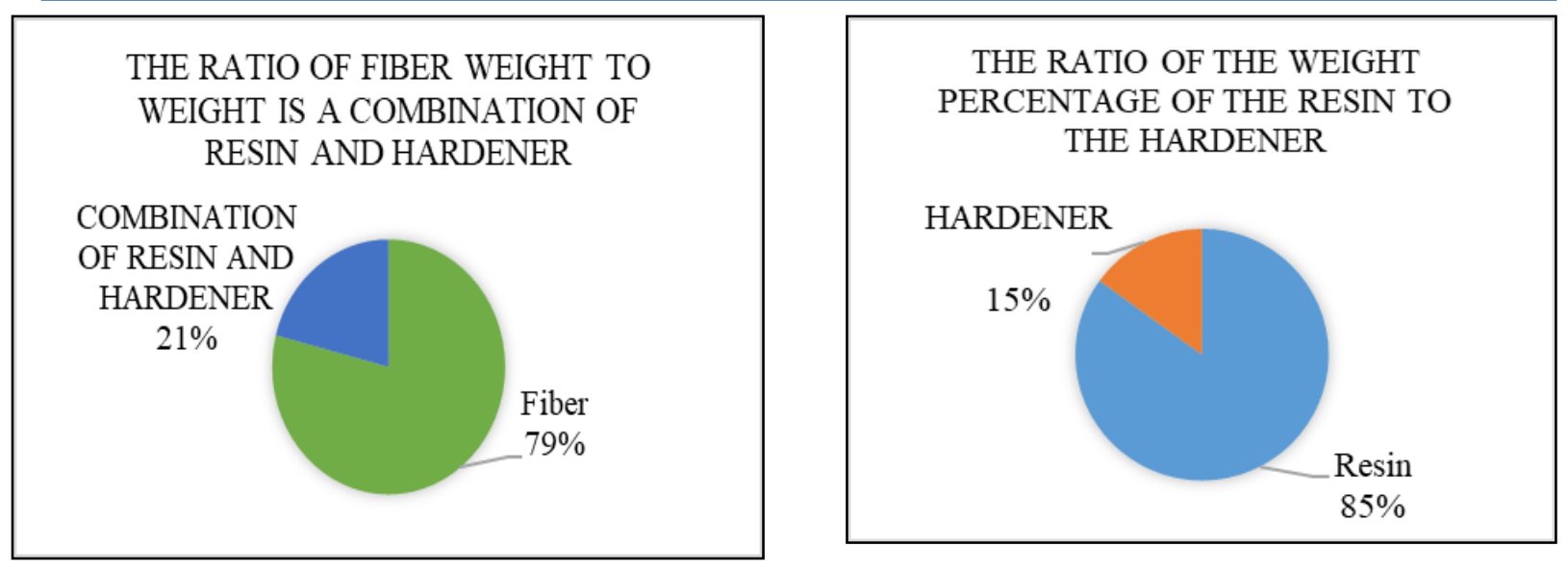

Figure 12: Specimen weight percentage chart.

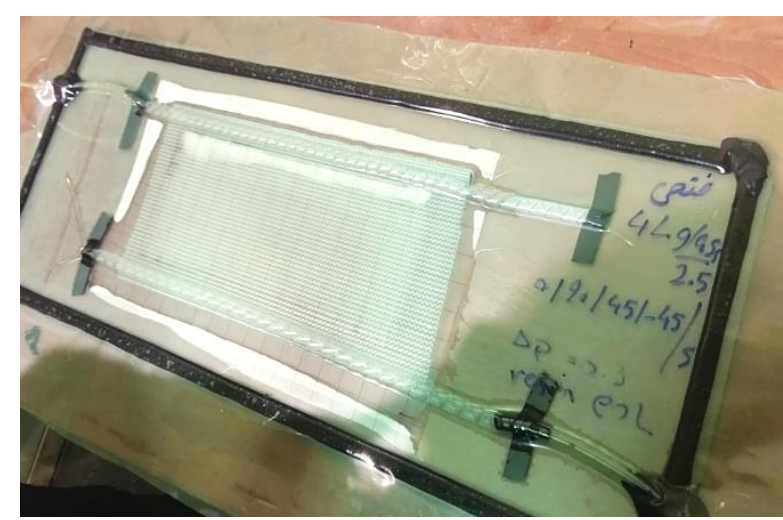

Resin injection stage in vacuum conditions.

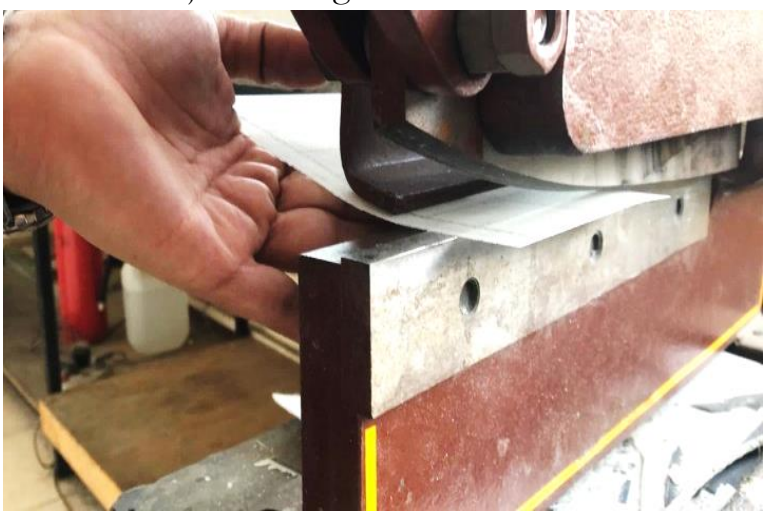

The accuracy of the dimensions of the cut piecework.

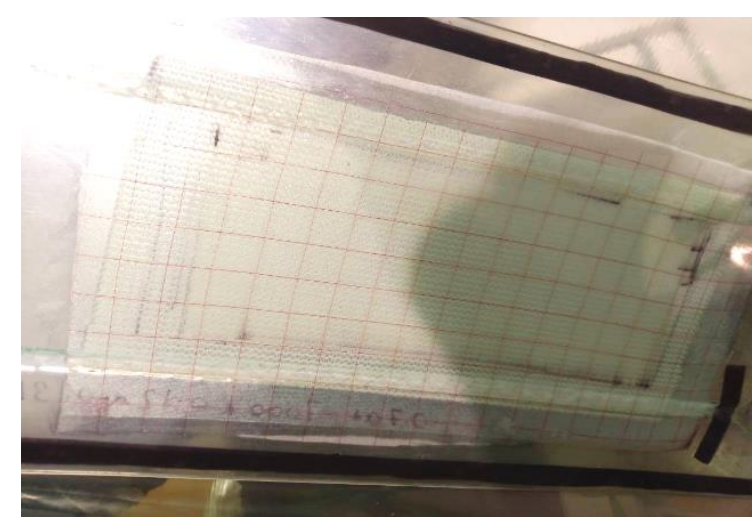

Image after injection.

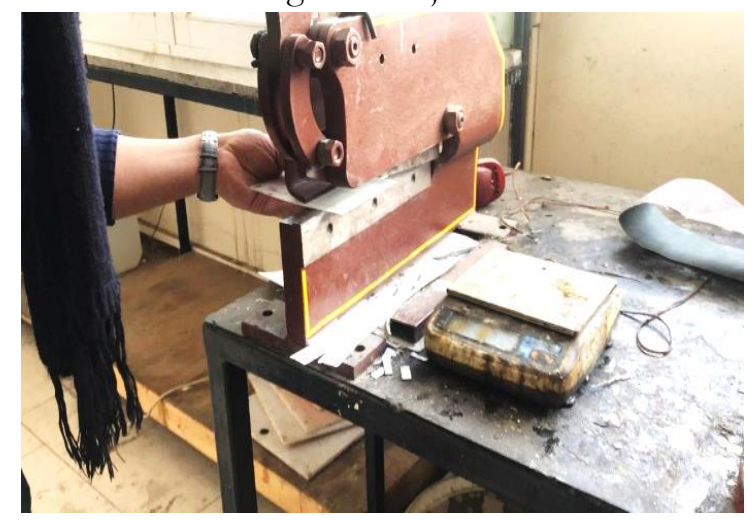

Cut the prepared page.

Figure 13: The cutting process of the pieceworks. 


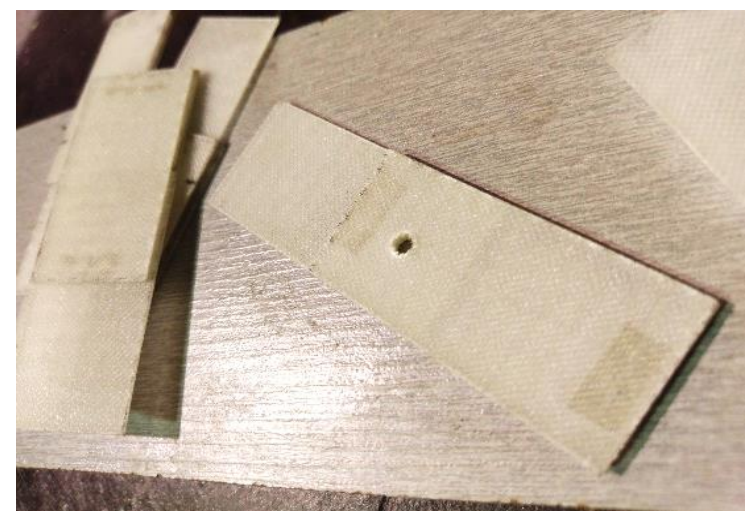

Specimen drilling operations.

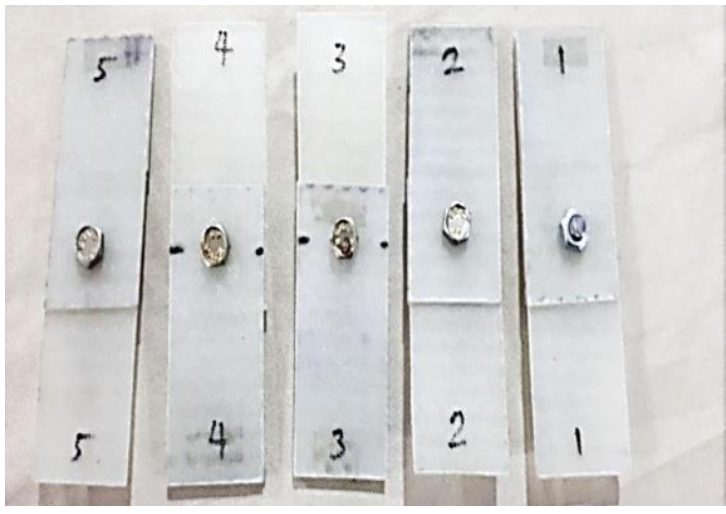

Pin joints.

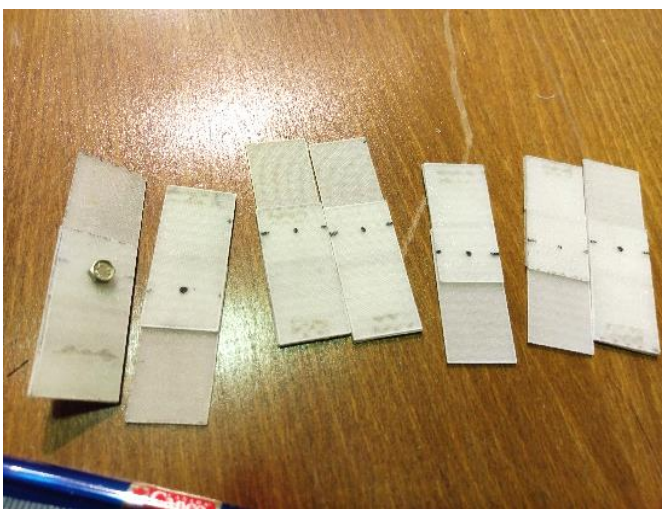

Determining the location of the perforation.

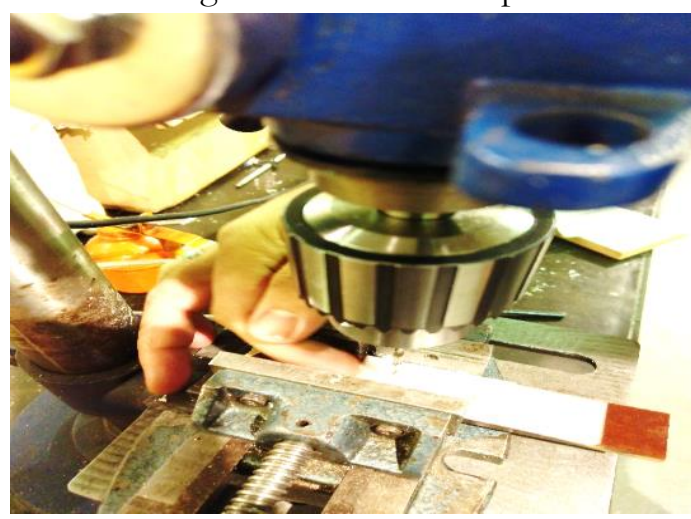

Plates drilling operations.

Figure 14: Drilling operations and joints of the specimens.

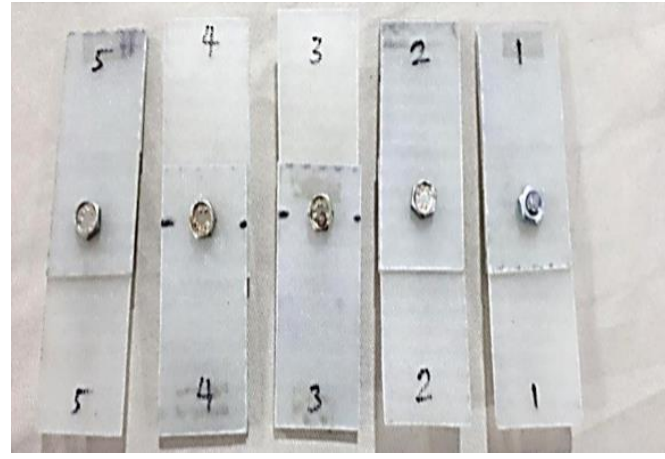

Figure 15: Specimens before the test.

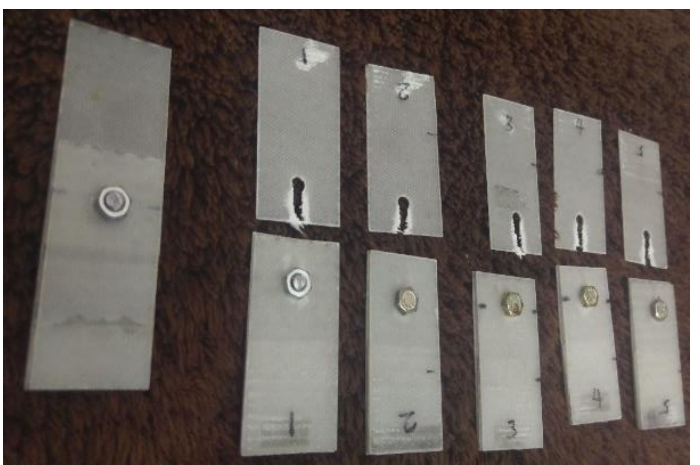

Figure 17: Failed the specimen in experimental test.

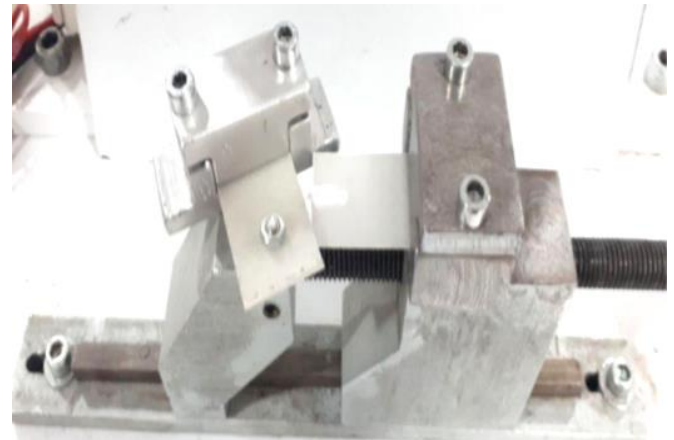

Figure 16: Failure the specimen after the test.

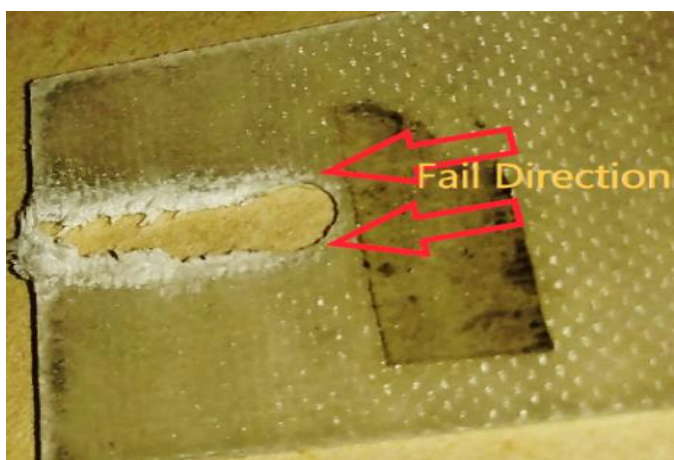

Figure 18: Fail direction in the specimen. 


\section{Results and Discussion}

Combining resin with hardener with a certain percentage of weight is mentioned in the chart of resin information. According to the resin information sheet, this weighting percentage is 15 to $85 \%$ higher than the resin hardener. Also, the weight percentage of fibers to the final resin of the part includes $79 \%$ of fibers and $21 \%$ of the composition of resin and hardener.

According to the data in the resin information sheet, the page made must be kept at room temperature for seven days to be fully curing.

After the screen is completely dry, open the bag and the screen will come out of the chamber. At this point, the screen is cut to the standard size required for testing by the guillotine. In the design of mechanical joints in composite materials, the selection of the dimensions of the perforated specimen is of particular importance, and in order to avoid adverse failure modes, the correct geometric parameters must be selected. Specimen cutting and drilling dimensions is shown in Table 3.

Table 3: Specimen cutting and drilling dimensions.

\begin{tabular}{cccc}
$\begin{array}{c}\text { Specimen } \\
\text { length }\end{array}$ & $\begin{array}{c}\mathrm{L}=50 \\
\mathrm{~mm}\end{array}$ & Specimen width & $\begin{array}{c}\mathrm{W}= \\
25 \\
\mathrm{~mm}\end{array}$ \\
\hline $\begin{array}{c}\text { The distance } \\
\text { from the center } \\
\text { of the hole to } \\
\text { the edge of the }\end{array}$ & $\begin{array}{c}\mathrm{e}-\mathrm{x} \\
=12.5\end{array}$ & $\begin{array}{c}\text { The distance } \\
\text { from the center } \\
\text { of the hole to } \\
\text { specimen width }\end{array}$ & $\begin{array}{c}\mathrm{e}-\mathrm{y}= \\
10 \\
\text { the edge of the } \\
\text { specimen length }\end{array}$ \\
\hline
\end{tabular}

To prevent problems during drilling, the plates are carefully removed with special tools. Also, the tendency of the multi-layered delamination during drilling is another strong plate under the main specimen, which reduces the pressure behind the drill as much as possible and prevents it from delamination and collapsing.

According to research on this type of loading, very little research has been done on this type of loading, and also the research found in this field has often been simulated.

\subsection{Tensile Impact Test}

After cutting and drilling, the specimens were joined together by a rigid pin and sent to Dana
Plastic the laboratory to ensure that tensile impact test was performed. The only available and healthy tensile impact test machine available in country Iran, according to ISO 8256 standard and D1822 tensile impact standard, is in Dana Plastic Test Company. The limitations of the machine are the placement of the specimen with a maximum size of $25 \times 80 \mathrm{~mm}$ and maximum thickness of $3 \mathrm{~mm}$. The maximum energy applied to the specimen is 25 joules, and the failure energy higher than this is not considered. The minimum number of tested for data accuracy is 5 tests. According to this standard, 5 specimens were prepared and tests were performed on these specimens.

After testing and failure the specimens, the test machine provides the failure energy number. The test results for the layup $\left[0^{\circ}, 90^{\circ},-45^{\circ}, 45^{\circ}\right] \mathrm{s}$ is shown in Table 4 and fracture energy of experimental results shown in Table 5 .

Table 4: The results of the tensile impact test.

\begin{tabular}{llr}
\hline $\begin{array}{l}\text { Measurement } \\
\text { index }\end{array}$ & $\begin{array}{l}\text { Standard } \\
\text { number }\end{array}$ & $\begin{array}{l}\text { Test } \\
\text { result }\end{array}$ \\
\hline \begin{tabular}{c} 
Fracture energy \\
of against \\
tensile strength \\
\cline { 2 - 2 }$(\mathrm{kJ})$
\end{tabular} & ISIRI 10919 & $\mathbf{5 2 7}$ \\
\cline { 2 - 2 } & & $\mathbf{5 2 3}$ \\
\hline $\begin{array}{c}\text { The ultimate strength response } \\
\text { against tensile impact failure }\end{array}$ & $\mathbf{5 6 1 6}$ \\
\hline
\end{tabular}

Table 5: Fracture energy of experimental results.

\begin{tabular}{cccc}
\hline Number & $\begin{array}{c}\text { Comparison } \\
\text { index }\end{array}$ & Unit & Result \\
\hline \multirow{4}{*}{1} & $\begin{array}{c}\text { Failure energy } \\
\text { against tensile } \\
\text { impact in } \\
\text { experimental } \\
\text { testing }\end{array}$ & & \\
& $\mathrm{kJ} / \mathrm{m}^{2}$ & 526 \\
& & \\
\hline
\end{tabular}

\section{Conclusion}

The important results obtained from the different of the hand lay-up method of this article, the results of the experimental test showed that the failure energy in the two states was 561 and 526 $\mathrm{kJ}$, respectively. The maximum stress entering the desired joint is related to the start of the $90^{\circ}$ angle layering. To achieve maximum strength, the hand 
lay-up can be designed with $\left[0^{\circ}, 45^{\circ}, 90^{\circ},-45^{\circ}\right] \mathrm{s}$ respectively. In order to balance the stresses applied to each layer according to its strength, in order to better transfer the stress, it is better to place the angles of $0^{\circ}$ and $90^{\circ}$ next to the angles of $45^{\circ}$ and $-45^{\circ}$. With different angles, the best state to select, is to start the lay-up with a $0^{\circ}$, because by selecting this state, the least stress is applied to the desired piecework. Under constant loading, changing the lay-up causes a change in the intensity of the tension in the desired joint. The most critical area in the stress concentration obtained in the mechanical joint is around the hole of the piecework. The presence of layers with $45^{\circ}$ fibers is very important, because these fibers in these layers have a significant role in increasing the resistance of the piecework under shear stresses due to the passage of stress lines along the hole; In other words, the maximum cut occurs at a $45^{\circ}$ angle, and these layers resist this shear stress.

\section{Competing Interests}

The authors declared that no conflict of interest exist in this publication.

\section{How to Cite this Article:}

Pourya Fathi \& Amin Moslemi Petrudi., "Investigation of Failure Criteria and Experimental Process of the Composite Specimen with Mechanical Joints under Tensile Loading” J. Mod. Mater.; Vol. 7, Issue 1, pp: 54-67, 2020. https://doi.org/10.21467/jmm.7.1.54-67

\section{References}

[1] Khan, Ruhul A., et al. "Comparative studies of mechanical and interfacial properties between jute and E-glass fiberreinforced polypropylene composites." Journal of Reinforced Plastics and Composites 29.7: 1078-1088, 2010. https://doi.org/10.1177/0731684409103148

[2] Banakar, Prashanth, H. K. Shivananda, and H. B. Niranjan. "Influence of fiber orientation and thickness on tensile properties of laminated polymer composites." International Journal of Pure and Applied Sciences and Technology 9.1:61, 2012.

[3] S. Long, X. Yao, and X. Zhang. "Delamination prediction in composite laminates under low-velocity impact," Composite Structures, vol. 132, pp. 290-298, 2015. https://doi.org/10.1016/j.compstruct.2015.05.037

[4] M. Singh, H. Bhunia, and J. Saini. "Effect of ply orientation on strength and failure mode of pin jointed unidirectional glass-epoxy nanoclay laminates," Defence Science Journal, vol. 65, no. 6, pp. 489-499, 2015.

[5] K. Senthil kumar, I. Siva, J. W. Jappes, S. C. Amico, F. Cardona, and M. Sultan. "Effect of inter-laminar fibre orientation on the tensile properties of sisal fibre reinforced polyester composites," in IOP Conference Series: Materials Science and Engineering, vol. 152, no.
1, p. $\quad 012055, \quad 2016$. https://iopscience.iop.org/article/10.1088/1757899X/152/1/012055/meta

[6] S. A. Jogi, M. M. Baloch, A. Chandio, I. A. Memon, and G. S. Chandio. "Evaluation of Impact Strength of Epoxy Based Hybrid Composites Reinforced with EGlass/Kevlar 49," Mehran University Research Journal of Engineering and Technology, vol. 36, no. 4, pp. 10091016, 2017. https://hal.archives-ouvertes.fr/hal-01705594

[7] Liu, B., Han, Q., Zhong, X., \& Lu, Z. "The impact damage and residual load capacity of composite stepped bonding repairs and joints". Composites Part B: Engineering, 158, 339-351, 2019. https://doi.org/10.1016/j.compositesb.2018.09.096

[8] A. Ondurucu, U. Esendemir and R.F. Tunay. "Progressive failure analysis of glass-epoxy laminated composite pinned-joints," Material and Design, No. 36, pp. 617-625, 2012. https://doi.org/10.1016/j.matdes.2011.11.031

[9] Taghipoor, Hossein, and Mohammad Damghani Noori."Experimental and numerical study on energy absorption of lattice-core sandwich beam." Steel and Composite Structures 27, no. 2: 135-147, 2018. https://doi.org/10.12989/scs.2018.27.2.135

[10] Harhash, Mohamed, Rose Rogin Gilbert, Stefan Hartmann, and Heinz Palkowski. "Experimental characterization, analytical and numerical investigations of metal/polymer/metal sandwich composites-Part 2: Free bending." Composite Structures 232: 111421, 2020. https://doi.org/10.1016/j.compstruct.2019.111421

[11] Aghaei-Ruzbahani, M., D. Shahgholian-Ghahfarokhi, and Gh Rahimi. "Experimental Analysis of Composite Sandwich Plates Buckling with Lozenge Core Using the Vibration Correlation Technique." Modares Mechanical Engineering 20, no. 5: 1399-1408, 2020. https://mme.modares.ac.ir/browse.php?a_id=33320\&sid $=15 \&$ slc_lang=en

[12] Li, Diyuan, Peng Xiao, Zhenyu Han, and Quanqi Zhu. "Mechanical and failure properties of rocks with a cavity under coupled static and dynamic loads." Engineering Fracture Mechanics 225: 106195, 2020. https://doi.org/10.1016/j.engfracmech.2018.10.021

[13] Yuan, Cheng, Wensu Chen, Thong M. Pham, Hong Hao, Jian Cui, and Yanchao Shi. "Interfacial bond behaviour between hybrid carbon/basalt fibre composites and concrete under dynamic loading." International Journal of Adhesion and Adhesives 99: 102569, 2020. https://doi.org/10.1016/j.ijadhadh.2020.102569

[14] Paranjpe, N. Strength and failure mode analysis of composite-to-composite and composite-to-metal single lap joints with different surface treatments (Doctoral dissertation, Wichita State University), 2016.

[15] Beheshty, M. H., Harris., \& Adam, T. An empirical fatigue-life model for high-performance fibre composites with and without impact damage. Composites Part A: Applied Science and Manufacturing, 30(8), 971-987, 1999. https://doi.org/10.1016/S1359-835X(99)00009-3

[16] Tsai, S. W., \& Wu, E. M. A general theory of strength for anisotropic materials. Journal of composite materials, 5(1), 58-80, 1971. https://doi.org/10.1177/002199837100500106

[17] Jones, R. M. Mechanics of composite materials. CRC press, 2014.

[18] Chamis, C. Failure criteria for filamentary composites. In Composite Materials : Testing and Design. ASTM International, 1969 